\title{
A New Method for Numerical Modeling of Heat Transfer in Thermal Insulations Products
}

\author{
Sohrab Veiseh \\ Building and Housing, Research Center
}

Iran

\section{Introduction}

Mineral fiber products are the most common group of thermal insulations currently in use. Heat transfer in these materials has been the subject of extensive investigations thanks to their numerous and varied applications as building and industrial insulations. Early studies addressed the problem of energy transport in terms of a simple theoretical model. They showed that gas conduction and radiation are the two dominant modes of heat transfer in fibrous insulations [Verschoor et.al. (1952), Bankvall (1974), Bhattacharyya (1980), and Larkin and Churchill (1959)].

Subsequent theoretical studies have been devoted to the solution of the radiative transfer equation in semi-transparent absorbing and isotropic scattering media. Tong and Tien (1980) developed analytical models for radiation in fibrous insulations. They (1983) modeled the radiative heat transfer by the two-flux and linear anisotropic scattering solutions compared well with experimental values. Transient heat transfer was also studied in other works Tong et. al. (1985-1986), and McElroy (1986).

Lee (1986, 1988, and 1989) and Lee and Cunnington (1998, and 2000) proposed radiation models which rigorously account for fiber morphology and orientation. Later models (1997, and 1998) used the radiative properties of the fibers. The contribution of radiative heat transfer through foam insulation was examined by Glicksman et al. (1987). Langlais et al. (1995) worked with the spectral two-flux model to analyze the effect of different parameters on radiative heat transfer. Zeng et al. (1995) developed approximate formulation for coupled conduction and radiation through a medium with arbitrary optical thickness. Daryabeigi (1999) developed an analytical model for heat transfer through high-temperature fibrous insulation. The optically thick approximation was used to simulate radiation heat transfer. He (2003) also modeled radiation heat transfer using the modified two-flux approximation assuming anisotropic scattering and gray medium.

Asllanaj, Milandel and their coworkers (2001, 2002, 2004, and 2007) studied different aspects of radiative-conductive heat transfer in fibrous media and made great contribution to the progress of this field. Yuen et al. (2003) used measured optical properties, the Mie theory, and the zonal method, to predict the transient temperature behavior of fibrous insulation.

Nisipeanu and Jones (2003) applied the Monte Carlo method to model radiation in the entire coarse fibrous media. Not only is this method computationally demanding, it also fails to 
take into account the contribution of conduction in radiation heat transfer. Moreover, it assumes random distribution of fibers in the media, while in reality the majority of fibers are oriented perpendicular to the heat flux.

The Monte Carlo method is essentially a time consuming process. As such, it has not been widely applied to model radiation heat transfer in previous studies. In the present work, however, distribution factors have been used to expedite computation. The number of calculations during each iteration is considerably reduced by this method. Radiation is coupled with conduction via the source term in the heat conduction equation. In addition, the present method considers fiber orientation perpendicular to heat flux, which is a more logical assumption than random orientation of fibers.

\section{Physical model and mathematical formulation}

As depicted in Fig. 1, the analytical model assumes that insulation is confined between two horizontal plates, having temperatures $T_{H}$ (top plate) and $T_{C}$ (bottom plate). Thus, the heat flux vector is aligned with the local gravity vector in order to eliminate free convection. Air inside the material is considered to be stagnant and dry and at atmospheric pressure. The heat transfer mechanism in fibrous insulations therefore includes solid conduction, gas conduction and radiation and the total heat flux is given by the sum of radiative and conductive heat fluxes:

$$
q_{t}=q_{c}+q_{r}
$$

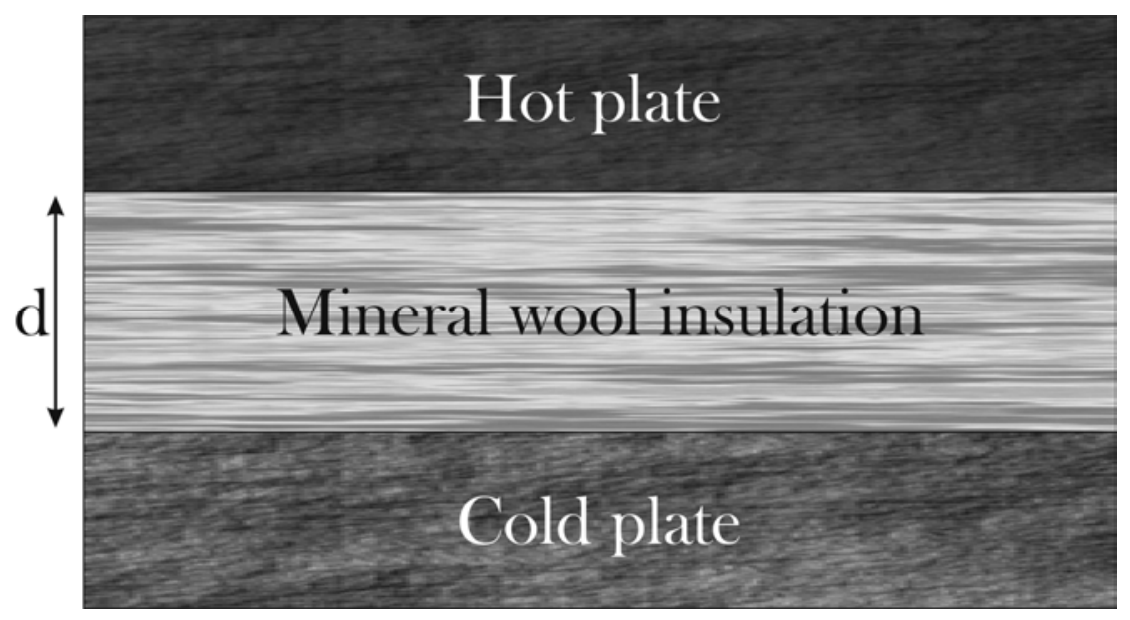

Fig. 1. Problem geometry

The steady state energy equation for a one-dimensional heat transfer is given by:

$$
\frac{d}{d x}\left(k_{c}(T) \frac{d T}{d x}\right)-\frac{d q_{r}(x)}{d x}=0
$$


where $k_{c}(T)$ is the effective thermal conductivity of the medium. The semi-empirical relation suggested by Langlais and Klarsfeld (2004) was used to model $k_{c}(T)$ for insulations made of silica fibers. The relation is based on experimental data obtained from a Guarded Hot Plate apparatus (Saint Gobain Research Center):

$$
k_{c}(T)=10^{-3}\left(0.2572 T_{m}^{0.81}+0.0527 \rho^{0.91}\left(1+0.0013 T_{m}\right)\right)
$$

where $\rho$ is the bulk density of the fibrous insulation, and $T_{m}$ is the mean temperature of the medium. This relation takes into account both air and fiber conduction as well as the contacts between fibers.

\section{Radiation modeling}

Radiation heat transfer through the medium considered in this work involves absorption, emission and scattering. The radiation modeling introduced here is based on the Monte Carlo Ray Trace (MCRT) method [Modest (2003), and Mahan (2002)], a statistical approach in which analytical solution of the problem is bypassed in favor of a numerical simulation, which is easier to carry out. The probabilistic description of radiation heat transfer by the MCRT method [Modest (2003), and Mahan (2002)] is based on the photon view of thermal radiation. The general approach in the MCRT method is to emit a large number of energy bundles from randomly selected locations on a given surface element and then to trace their progress through a series of reflections until they are finally absorbed on a surface element [Mahan (2002)]. As radiation heat transfer is a three dimensional phenomenon, direct simulation is utilized to model radiation heat transfer in fibrous media.

Equation (2) is a one-dimensional energy equation therefore it should be coupled with one dimensional radiative heat transfer equation. Accordingly, results for a three-dimensional direct modeling need to be averaged out into a one-dimensional media. The radiative heat flux term in Eq. (2) indicates a radiative heat source. Therefore radiative heat sources have to be found in parallel planes along the $x$-axis. The one-dimensional radiation heat transfer equation for computing these radiative heat sources can be written as:

$$
\begin{aligned}
q_{r}(x) & =\sigma\left(\varepsilon_{H} D_{H i} T_{H}^{4}-\varepsilon_{i} D_{i H} T_{i}^{4}\right)+\sigma\left(\varepsilon_{i} D_{i C} T_{i}^{4}-\varepsilon_{C} D_{C i} T_{C}^{4}\right) \\
& +\sigma \sum_{j=1}^{i}\left(\varepsilon_{j} D_{j i} T_{j}^{4}-\varepsilon_{i} D_{i j} T_{i}^{4}\right)+\sigma \sum_{j=i+1}^{n}\left(\varepsilon_{i} D_{i j} T_{i}^{4}-\varepsilon_{j} D_{j i} T_{j}^{4}\right)
\end{aligned}
$$

where $i$ indicates the plane number at the location of $x, H$, and $C$ indicate the hot and cold bounding plates. $D_{H i}$ and $D_{C i}$ are the the radiation distribution factor $(R D F)$ of the hot and cold bounding plates to the fibers' plane respectively, $D_{i H}$ and $D_{i C}$ are the RDF of the fibers' plane to the hot and cold bounding plates respectively. $D_{i j}$ and $D_{j i}$ are the $R D F$ between different elements within the media. $D_{i j}$ is defined as the fraction of the total radiation emitted diffusely from element $i$ and absorbed by element $j$, due to both direct radiation and to all possible diffuse and specular reflections within the enclosure [Mahan (2002)]. 
The first term on the right hand side of Eq. (4) represents the radiative heat flux emitted by the hot bounding plate and absorbed by the fibers in plane $i$, the second term represents the radiative heat flux emitted by the fibers in plane $i$ and absorbed by the cold bounding plate, and the third and fourth terms represent the resultant interaction radiative heat flux between the fibers in plane $i$ and other fibers within the media in different planes.

From Eq. (4), it is clear that the radiative distribution factor is required for two different cases; $R D F$ among fibrous planes and the $R D F$ of the fibrous planes to the boundary plates. Hence, the problem is to find the radiation distribution factor for these two cases as a function of relative distance.

Application of the reciprocity relation, Eq. (5), readily gives the distribution factors from other planes to the source plane. A similar procedure is adopted to compute the RDF of the fibers to the bounding plates.

$$
\varepsilon_{i} A_{i} D_{i j}=\varepsilon_{j} A_{j} D_{j i}
$$

where $\varepsilon_{\mathrm{i}}$ and $\varepsilon_{\mathrm{j}}$ are the emissivity of the fibers $i$ and $j . A_{i}$ and $A_{j}$ are the surface areas of fibers planes $\mathrm{i}$ and $\mathrm{j}$.

It is assumed that for the limited temperature range considered, the radiative distribution factor is not a function of temperature. Therefore, it is possible to compute the RDF of the fibers for the mean temperature properties and it is not required to recompute distribution factors in each iteration procedure.

In addition, as the fibers are distributed randomly in the plates normal to the heat flux, the $R D F$ of the fibers is not a function of their position but of their relative distance. For instance it is possible to say that $D_{i j}$ for fiber $i$ has the same value for all fibers $j$ which are located at the same distance from fiber $i$. Therefore, it is only required to compute one fiber's RDF in the assumed simulated cylindrical media and the results can be utilized for the entire domain. To compute the RDF of the fibers to the plates, it is possible to compute the RDF of the plate to the fibers and apply the reciprocity rule (Eq. 5).

The following procedure is adopted for computing the RDF of the fibers:

A simulated cylindrical media with a specific radius and infinite height is assumed in which fibers are randomly located parallel to cylinder's axis as shown in Fig. 2. It is assumed that the fibers are distributed randomly with a uniform distribution in the media and the number of fibers per volume in the media is a function of the material's porosity. As the average fiber diameter and the porosity of the material are measurable, it is possible to define the number of the fibers in the defined cylinder. The radius of the assumed cylinder should be long enough so that no emitted energy bundle can escape the media. This length is directly related to the optical thickness of the fibers.

Figure 3 shows the flow chart of the MCRT for the given problem. RDF of the fibers has a rapidly decaying exponential behavior. Hence the cylinder defined for the determination of the RDF could have a short diameter as compared to the thickness of the real fibrous media. This considerably reduces simulation time. 


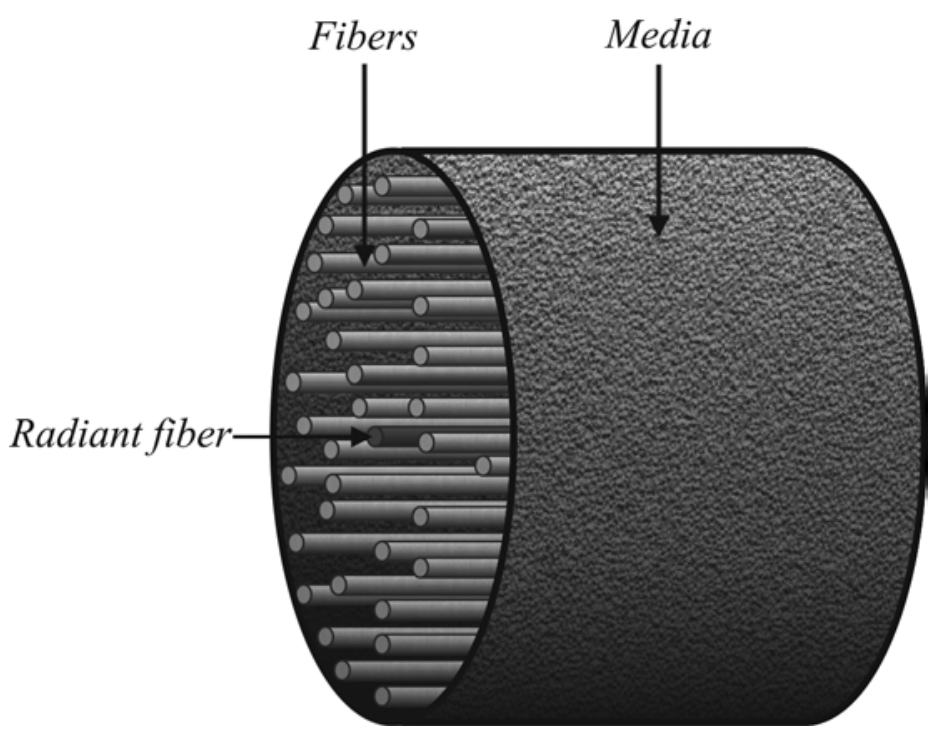

Fig. 2. Simulated cylindrical fibrous media for computing the radiation distribution factor of the fibers 


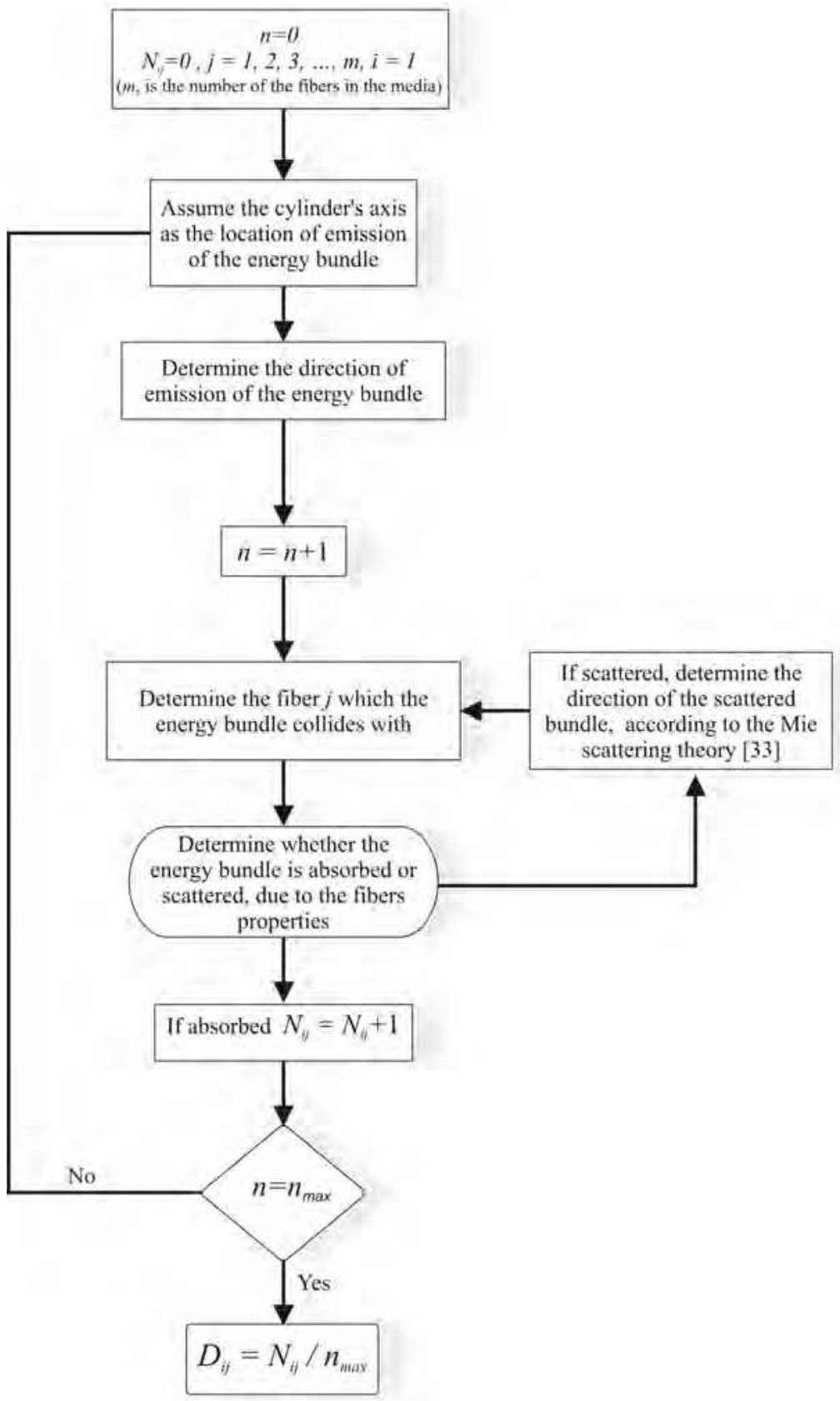

Fig. 3. Flow chart of the MCRT method for computing the fibers radiation distribution factor 
The same procedure can be used to compute the distribution factor of the fibers to the bounding plates. In this case the radiant fiber is assumed to be at the center of a semi cylinder, on the boundary surfaces, as shown in Fig. 4. The plate is assumed to be opaque. The $R D F$ of the plate to the fibers is determined by direct Monte Carlo simulation, and by employing the reciprocity rule the $R D F$ of the fibers to the plates can readily be computed. Figure 5 shows the flow chart of the MCRT for the given problem.

The Mie scattering phase function is applied to determine the direction of the scattered radiant from fibers [35]. The Mie phase function depends on the mean diameter, index of refraction of the fibers and the prominent wave length of the media.

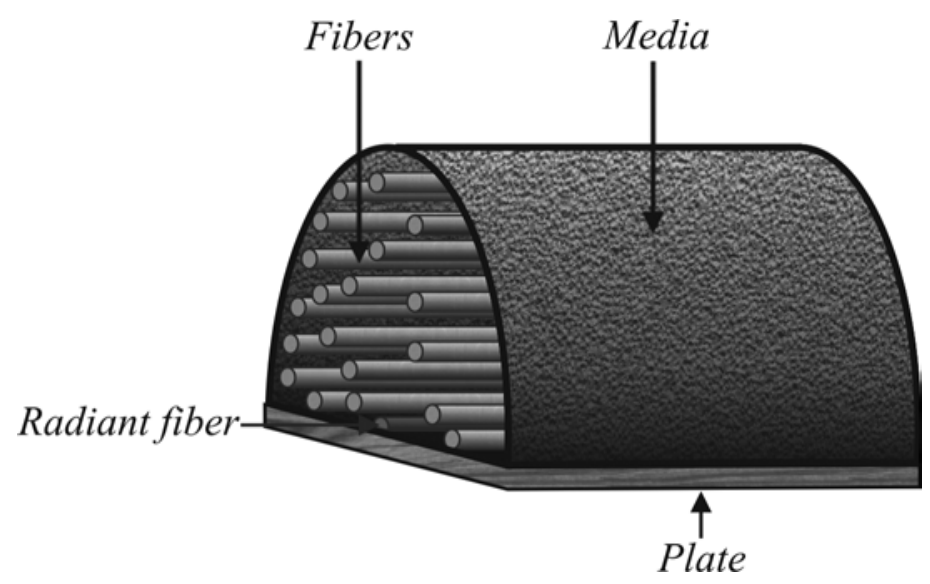

Fig. 4. Simulated semi cylindrical fibrous media for computing the radiation distribution factors of the fibers to the plate

\section{Computational procedure}

Considering the nature of the problem which involves combined radiation and conduction equations; the solution of the coupled equations involves an iterative procedure. Therefore, in every iterations the conduction and radiation equations should be solved. Since RDFs need not be recomputed in every iteration, the computations are considerably more efficient as compared to those methods in which radiation is fully coupled (such as: discrete ordinate method, spherical harmonics, or zonal method).

To solve the energy equation, the simple implicit (Laasonen) method [Anderson (1984)] is used to discretize implicit time and space derivatives. This method has a first-order accuracy with a truncation error of $\mathrm{O}\left[\Delta \mathrm{\tau},(\Delta \mathrm{x})^{2}\right]$ and is unconditionally stable. Several grids were tried with 500, 1000, 2500, 5000, and 10000 nodes; comparing the results obtained showed that the 5000 node grid was sufficient for this case study. 


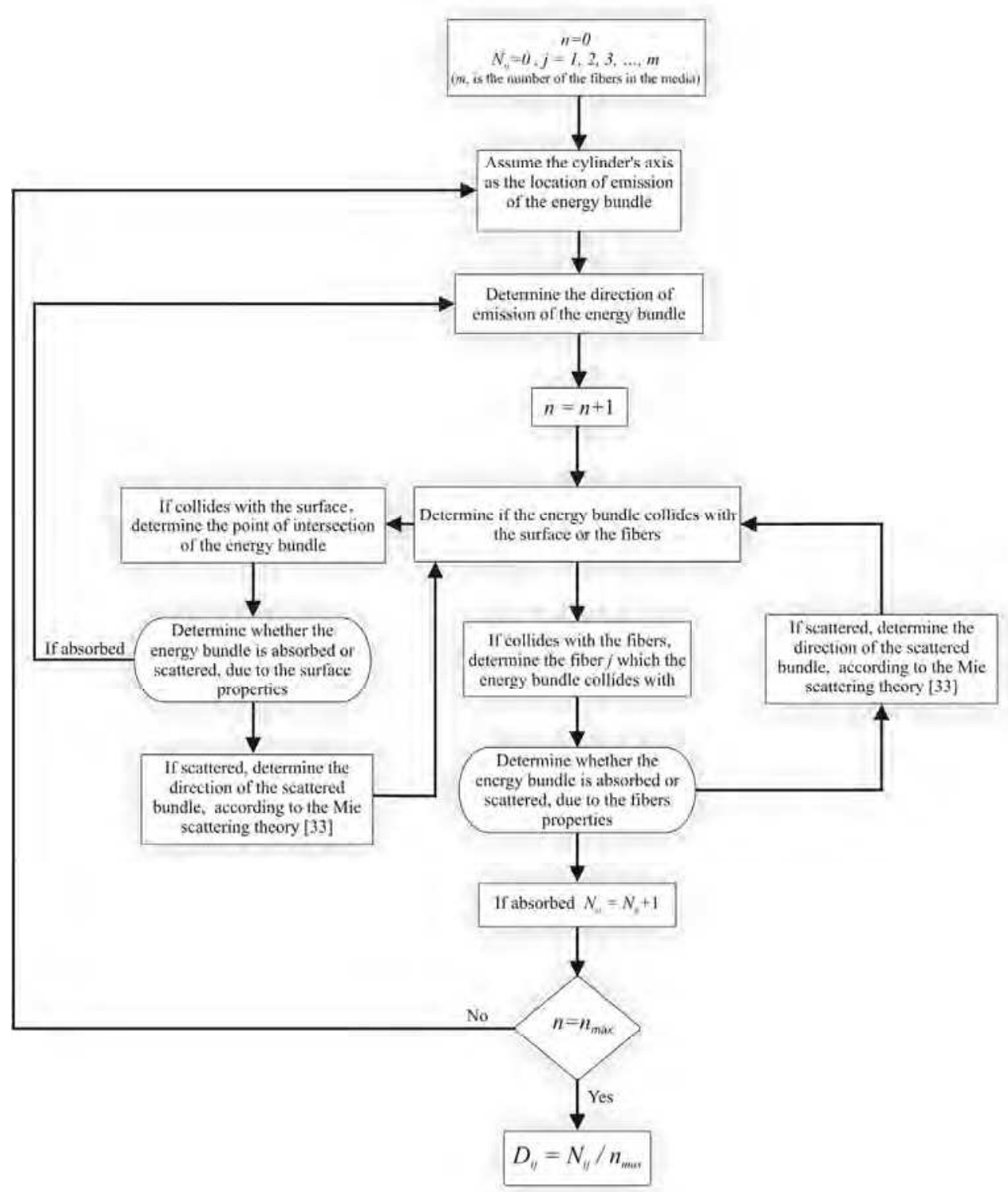

Fig. 5. Flow chart of the MCRT method for computing the fibers radiation distribution factor to the plate 
The flow chart of the corresponding method is given in Fig. 6. The iterations continue until convergence of the iterative procedure. The convergence criterion is based on the rms of the difference between temperatures of two subsequent iterations as defined below:

$$
\sqrt{\frac{1}{n} \sum_{j=1}^{n}\left(T_{j}^{P+1}-T_{j}^{P}\right)^{2}}<10^{-4}
$$

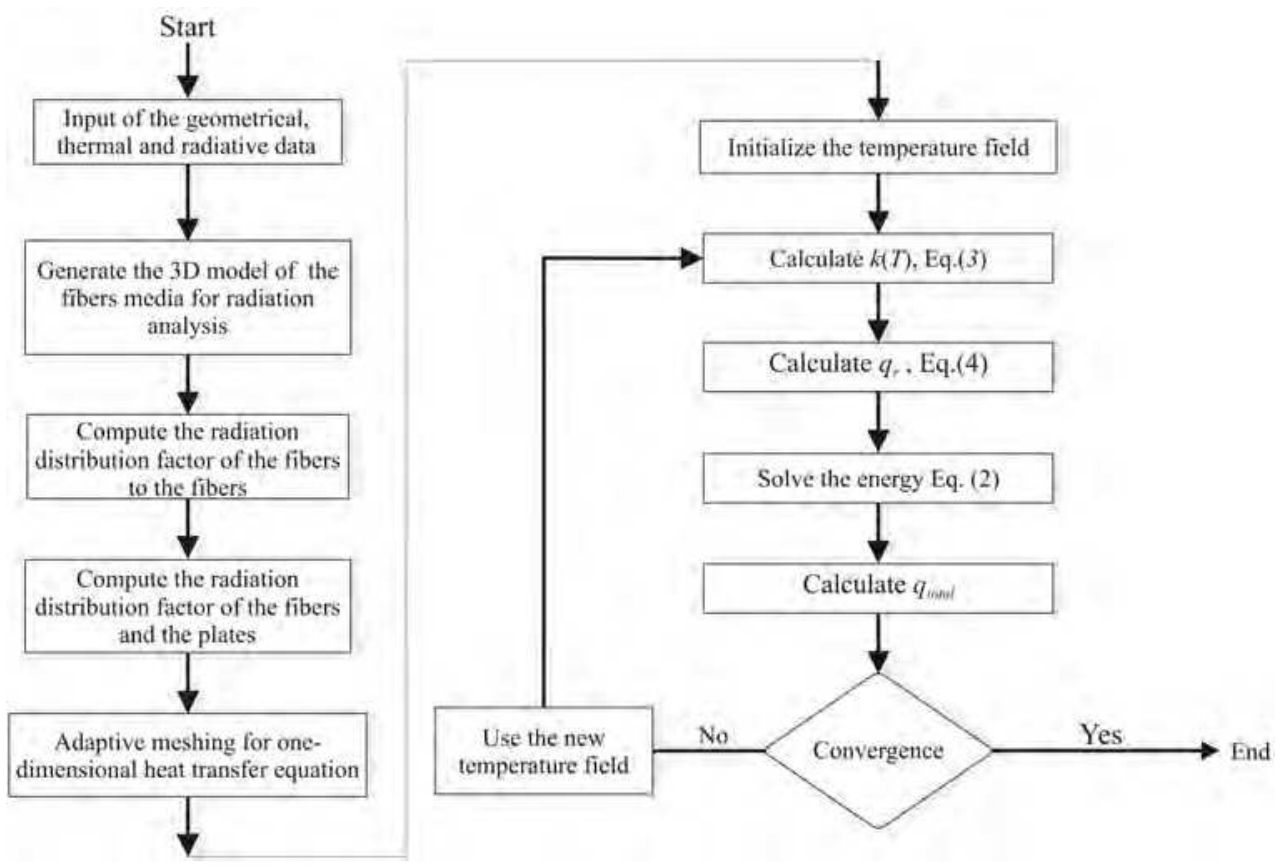

Fig. 6. Flow chart for the solution of the coupled equations

where $T_{j}^{P}$ indicates temperature inside the media at location $i$ and at iteration $p$, and $n$ indicates the number of grid nodes.

The real condition of the Heat Flow Meter (HFM) apparatus was used in the proposed model. The boundary temperatures were $0^{\circ} \mathrm{C}$ and $20^{\circ} \mathrm{C}$. The thickness of the media was taken as $5 \mathrm{~cm}$. The experiments conducted at Building and Housing Research Center (BHRC) showed that the mean diameter of fibers from samples studied was seven microns. The averaged index of refraction for glass is considered to be $1.49+1 \times 10^{-4} i$, where $i$ is imaginary unit (derived from the Hsieh and $\mathrm{Su}$, [Hsieh (1979)]. As the mean temperature is $283 \mathrm{~K}$, from Wien's displacement law [Siegel, and Howell (2002)], the wavelength from which the largest amount of radiative energy is transmitted is $\lambda=10 \mu \mathrm{m}$. Therefore, the radiative properties are the same as the properties proposed by Roux [Roux (2003)] in this wavelength. A boundary surface emissivity of 0.9 (as declared by Netzsch, the manufacturer of the HFM apparatus) is used for these computations. 


\section{Discussion}

\subsection{Numerical results}

Figure 7(a) shows the cross section of the simulated fibrous media for a density of $500\left(\mathrm{~kg} / \mathrm{m}^{3}\right)$ and Fig. $7(\mathrm{~b})$ shows the cross section contour of the radiation distribution

(a)
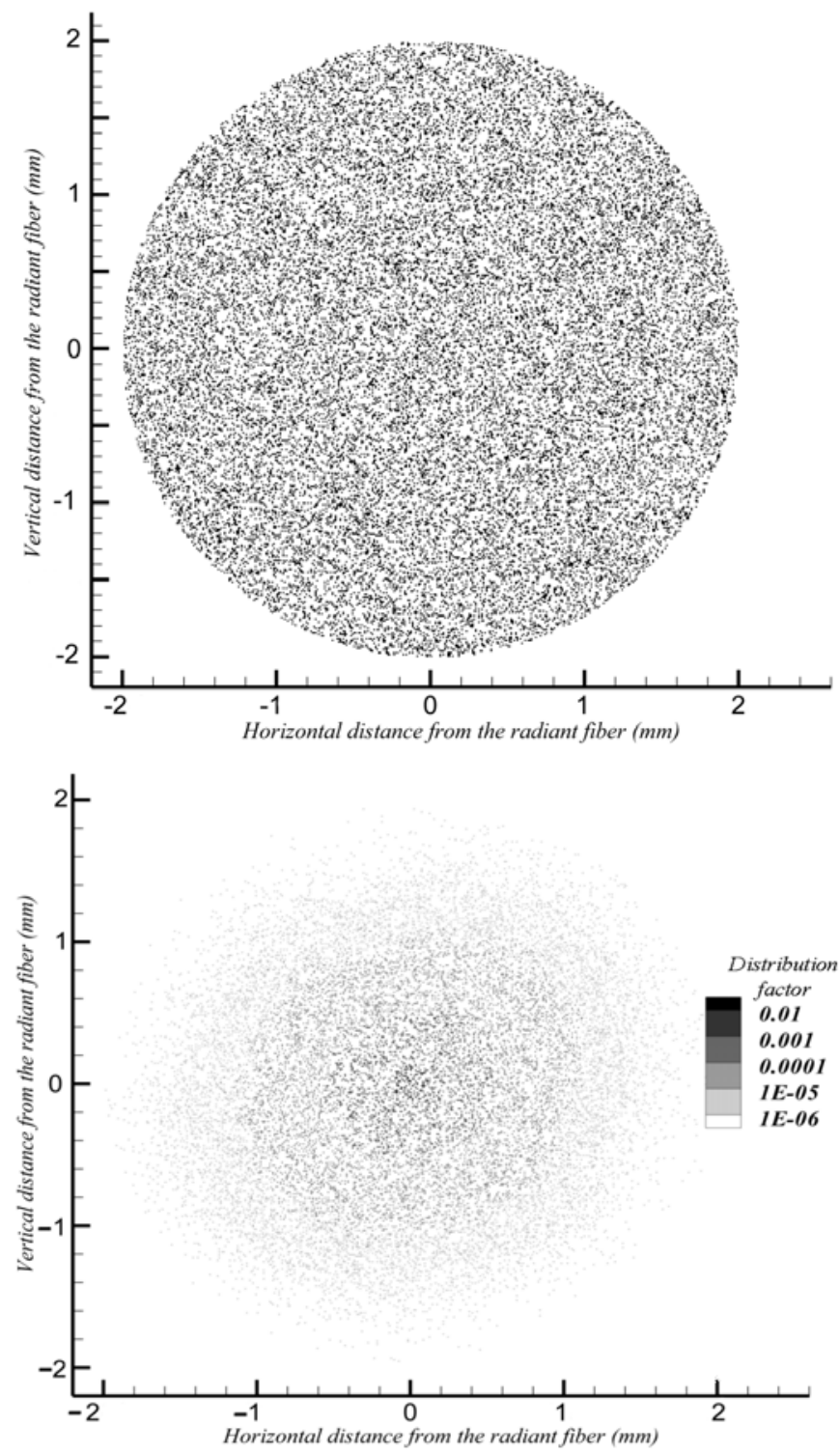

(b)

Fig. 7. (a) Cross section of the simulated cylindrical fibrous media for $\rho=500 \mathrm{~kg} / \mathrm{m}^{3}$, (b) Cross section contour of the radiation distribution factor for $\rho=500 \mathrm{~kg} / \mathrm{m}^{3}$ 
factor for the same density. Figure 7 clearly shows that the radiative distribution factor decays rapidly, obviating the need for determination of the $R D F$ for the entire media.

The results of the effective thermal conductivity, $k_{e}$ (Eq. (7)), radiative conductivity, $k_{r}$, (Eq. (8)), and the air and glass fiber conductivity, $k_{c}$, (Eq. (9)) computed with the current method for different densities between 5 and $500\left(\mathrm{~kg} / \mathrm{m}^{3}\right)$ are shown in Fig. 8 .

$$
\begin{aligned}
& k_{e}=q_{t} /\left(T_{H}-T_{C}\right) \\
& k_{r}=q_{r} /\left(T_{H}-T_{C}\right) \\
& k_{c}=q_{c} /\left(T_{H}-T_{C}\right)
\end{aligned}
$$

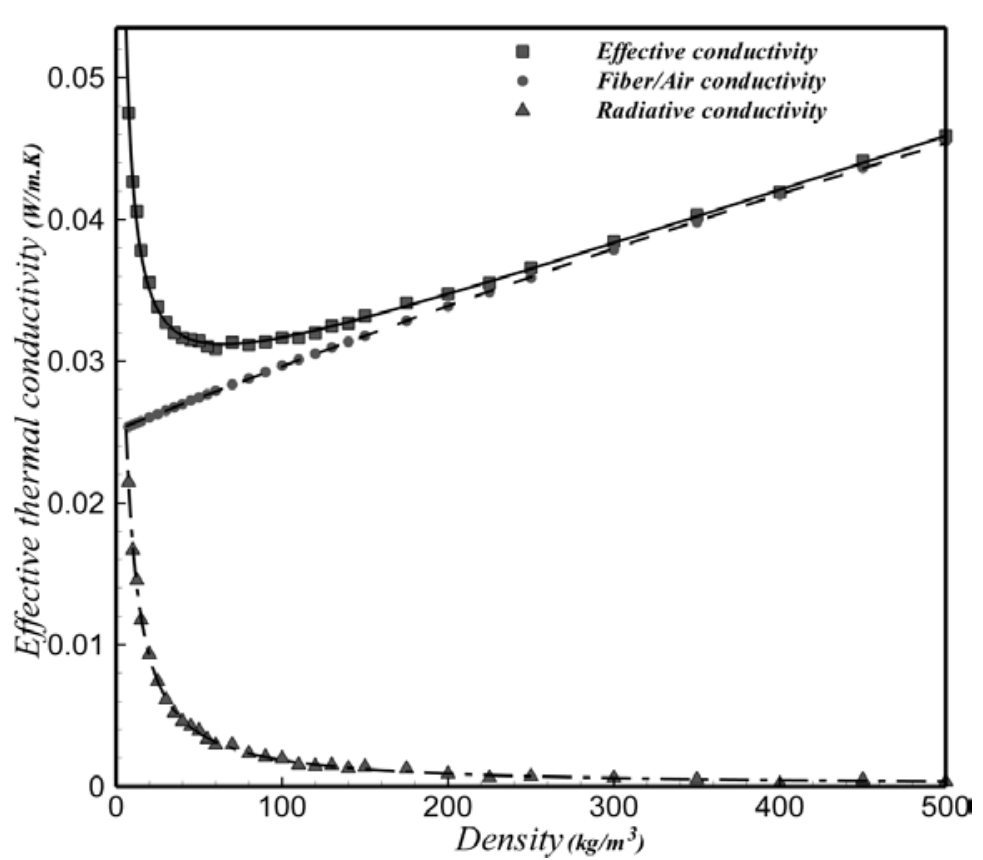

Fig. 8. Effective thermal conductivity, air/fiber conductivity and the radiation conductivity of glass fiber for different densities and mean temperature of $10^{\circ} \mathrm{C}$

Total heat flux, conduction and radiation heat flux of fiber glass under steady state condition for $\rho=50 \mathrm{~kg} / \mathrm{m}^{3}$ and $\rho=7.5 \mathrm{~kg} / \mathrm{m}^{3}$ according to the position in the medium, are shown in Figs. 9(a) and 9(b), respectively. As is seen in Fig. 9(a, b) total heat flux for $\rho=7.5 \mathrm{~kg} / \mathrm{m}^{3}$ is $33.8 \%$ greater than the total heat flux for the $\rho=50 \mathrm{~kg} / \mathrm{m}^{3}$. In addition, the radiation heat flux is $12.6 \%$ of the total heat flux for $\rho=50 \mathrm{~kg} / \mathrm{m}^{3}$, and $45.2 \%$ of the total heat flux for $\rho=7.5 \mathrm{~kg} / \mathrm{m}^{3}$. 


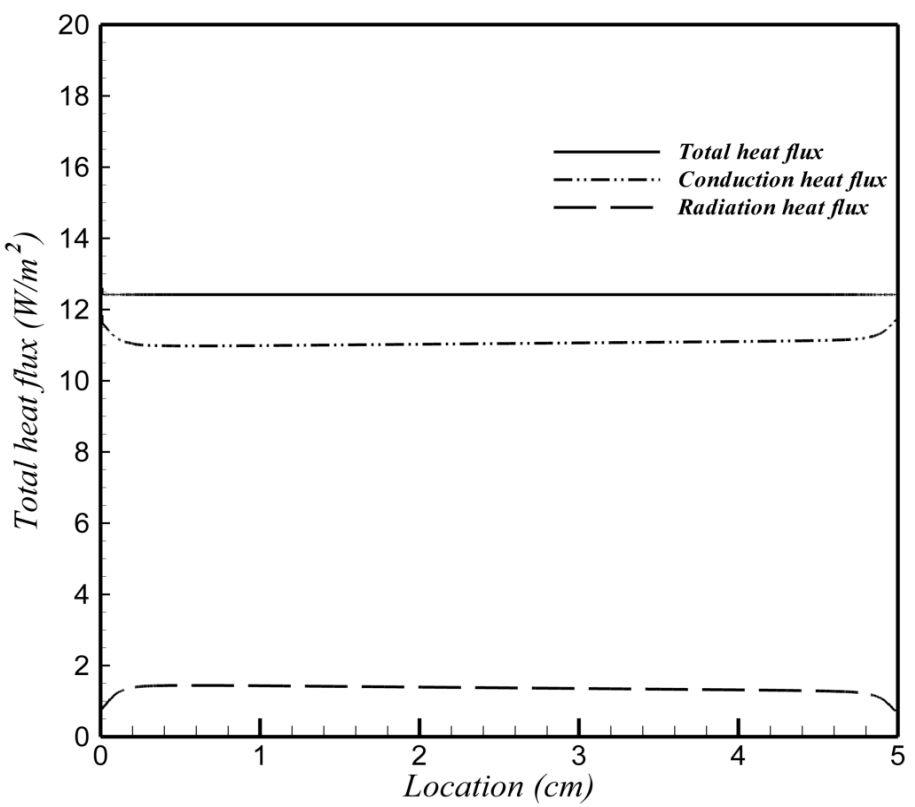

(a)

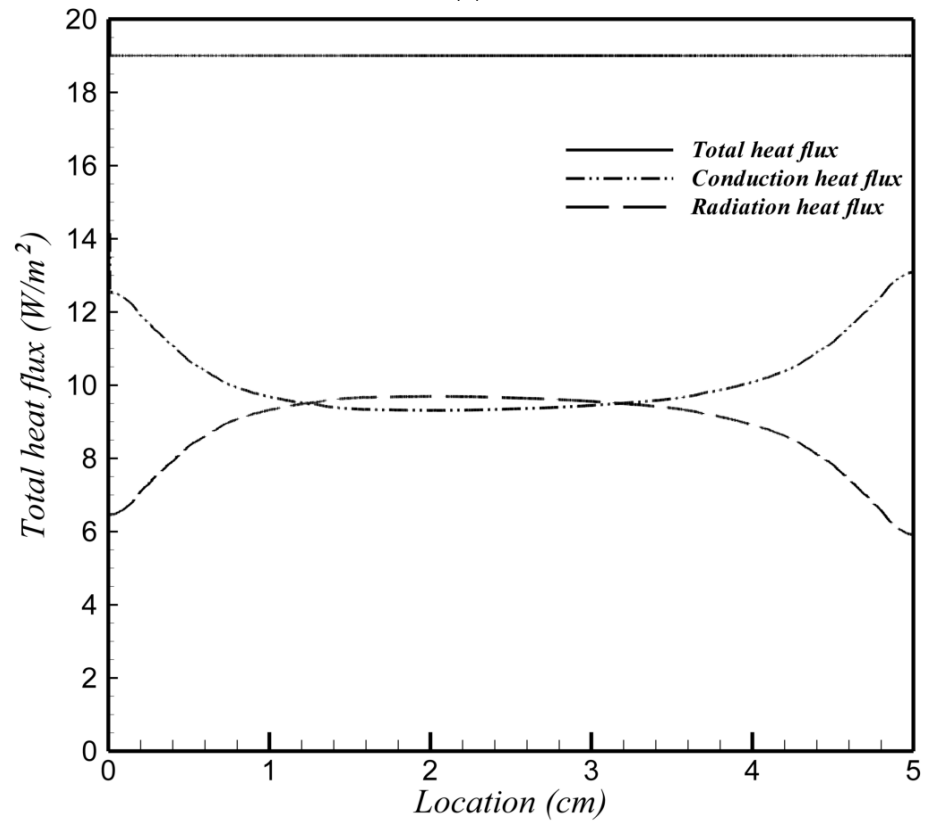

(b)

Fig. 9. Total heat flux, conduction and radiation heat flux of fiber glass at steady state condition and mean temperature of $10^{\circ} \mathrm{C}$, according to the position in the medium:

(a) $\rho=50 \mathrm{~kg} / \mathrm{m}^{3}$, (b) $\rho=7.5 \mathrm{~kg} / \mathrm{m}^{3}$ 
The temperature profiles within the medium for mean temperature of $10^{\circ} \mathrm{C}$, and $\rho=50 \mathrm{~kg} / \mathrm{m}^{3}$ and $\rho=7.5 \mathrm{~kg} / \mathrm{m}^{3}$ are shown in Fig. 10 .

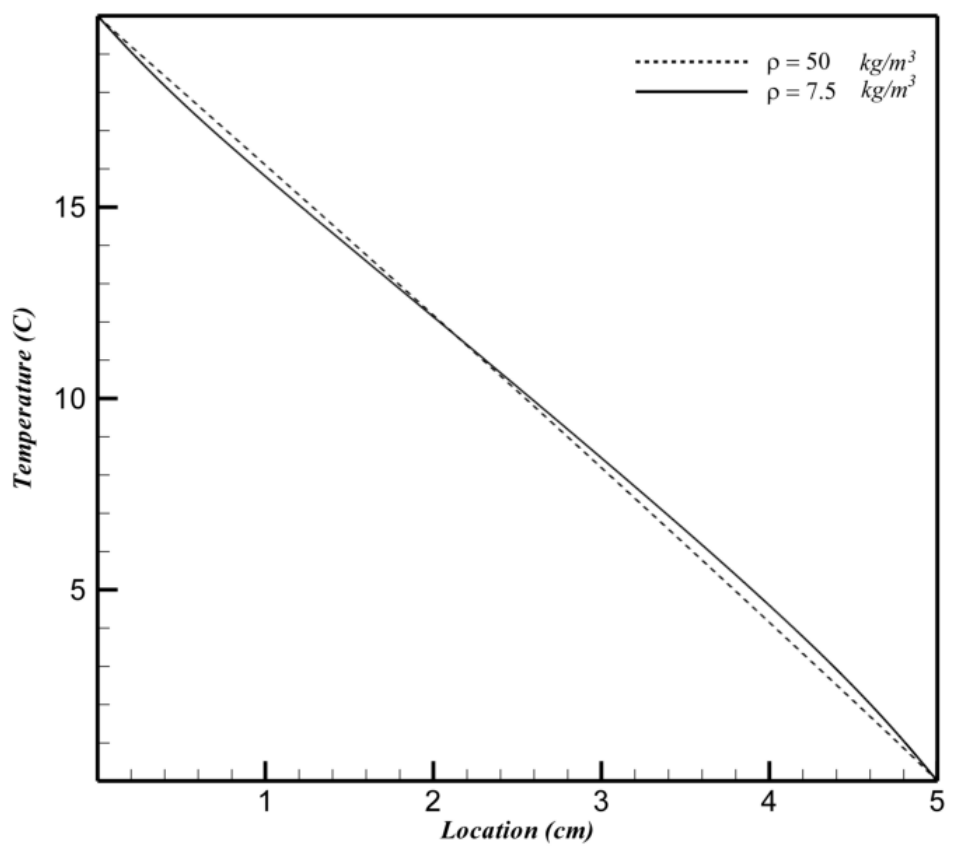

Fig. 10. Temperature profiles within the medium for mean temperature of $10^{\circ} \mathrm{C}$, and $\rho=50 \mathrm{~kg} / \mathrm{m}^{3}$ and $\rho=7.5 \mathrm{~kg} / \mathrm{m}^{3}$

\subsection{Experimental measurements}

A large number of experiments were performed at BHRC on mineral wool insulations for determination of thermal conductivity and microstructural analysis. The stereo-microscopy observations of the samples showed that most of the fibers are oriented parallel to the faces and the boundaries (Fig. 11). Thus, the direction of heat flow is perpendicular to the direction of the majority of fibers. Accordingly the model's assumption of parallel cylindrical fibers is well justified. 


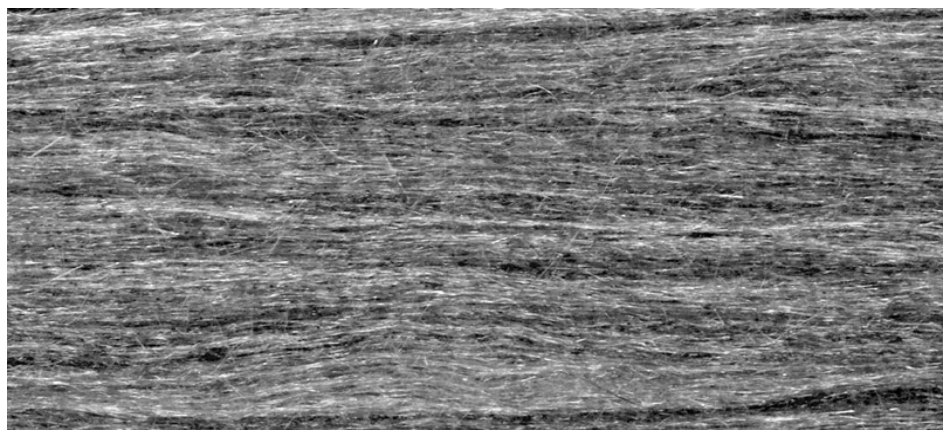

Fig. 11. Stereo micrograph of glass wool

Scanning electron microscopy (SEM) showed that the diameter of the fibers is 6.2-8.8 microns. The mean diameter of fibers determined with SEM is about $7 \mu \mathrm{m}$. As the diameters of these fibers are much smaller than their length, the length can be assumed infinite in the model in comparison to the diameter.

The effective thermal conductivity of more than 300 different samples of glass fiber products with densities ranging from 6 to $120 \mathrm{~kg} / \mathrm{m}^{3}$ were measured. The conductivity measurements were carried out at BHRC with a heat flow meter (HFM) apparatus according to EN12667 (2001). The HFM apparatus used is a single-specimen symmetrical device that consists of two heat flow meters and allows the detection of the heat transfer rate on both the hot and cold sides of the specimen. The cold and hot plate temperatures were set at $0^{\circ} \mathrm{C}$ and $20^{\circ} \mathrm{C}$, respectively. The samples were dried in a ventilated oven and then brought into equilibrium with laboratory air temperature. To prevent moisture from migrating to the specimens during the test, specimens were enclosed in a vapor-tight envelope. The accuracy of thermal conductivity determination was better than $\pm 3 \%$. Measurement repeatability was found to be better than $\pm 1 \%$ both when the specimen was maintained in the apparatus and removed and mounted after a long interval. For bulk density determination the accuracy in the measurements of specimen length, width, and thickness were better than $\pm 1 \%$. The maximum uncertainty in measured specimen thickness due to departures from a plane was $0.5 \%$. The maximum uncertainty in the determination of specimen mass was $0.5 \%$.

\subsection{Comparison of numerical and experimental results}

The numerical model was validated by comparing the predicted effective thermal conductivity with measured data from the research at BHRC, those obtained in Technical Research Institute of Sweden (SP) [Jonsson (1996)], and those presented in ASHRAE handbook [ASHRAE (1997)] for fibers with $5.6 \mu \mathrm{m}$ diameter.

The comparison of the effective thermal conductivity of glass fiber having different densities obtained from the proposed model and the experimental results, are shown in Fig. 12. It can be seen that in lower densities, where radiation is dominant, experimental results conform excellently to the model predictions. Table 1 shows the percentage of difference between the results of the proposed model and the experimental results. The model predictions are in good agreement with measurement results. 


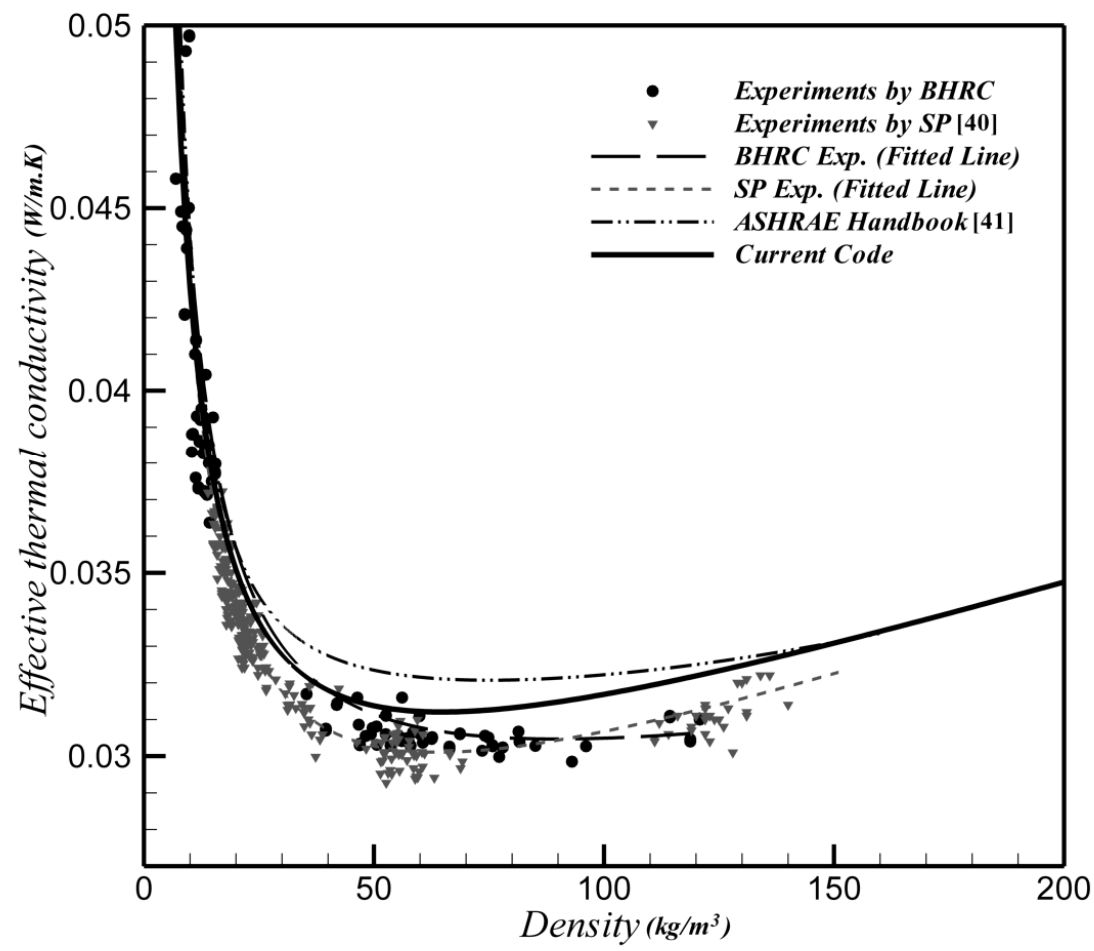

Fig. 12. Comparison of effective thermal conductivity between current method and experimental results of SP [Jonsson (1996)] and ASHRAE [ASHRAE (1997)] and those obtained in a research project at BHRC

\begin{tabular}{lll}
\hline \multicolumn{1}{c}{ Experiments done by } & \multicolumn{1}{c}{$\begin{array}{c}\text { Density Range } \\
\left(\mathrm{kg} / \mathrm{m}^{3}\right)\end{array}$} & $\begin{array}{c}\text { Percent difference of proposed } \\
\text { model and experiments }\end{array}$ \\
\hline \hline SP [40] & $10-140$ & $3.3 \%$ \\
ASHRAE [41] & $8-160$ & $2.6 \%$ \\
BHRC & $6-120$ & $1.3 \%$ \\
\hline
\end{tabular}

Table 1. Percent difference between effective thermal conductivity of the model and the experiments by SP, ASHRAE and performed in a research project at BHRC

\section{Conclusion}

This chapter introduces a new numerical modeling of steady state heat transfer for combined radiation and conduction in a fibrous medium for the prediction of the effective thermal conductivity. Radiant heat transfer in mineral wool insulations is modeled by the statistical-based Monte Carlo method. A finite difference approach has been developed to 
solve the governing coupled radiation and conduction heat transfer equations. The numerical model was validated by comparison with effective thermal conductivity measurements at different densities. The proposed method is easy to code and computationally efficient. The model is able to sort out individual contributions of conduction and radiation heat transfer mechanisms in these materials.

\section{References}

Abu-Eishah S. I., Haddad Y., Solieman A., and Bajbouj A., 2004, "A New Correlation for the Specific Heat of Metals, Metal Oxides and Metal Fluorides as a Function of Temperature", Bahia Blanca, Vol. 34, No. 4, pp 257-265.

Andersen, F. M. B., and Dyrbol, S. , 1997, "Comparison of Radiative Heat Transfer Models in Mineral Wool at Room Temperature", Proc. $2^{\text {nd }}$ International Symposium on Radiation Transfer, Kusadasi, Turkey, vol. 1, pp. 607-619.

Andersen F. M. B., and Dyrbol, S. , 1998, "Modeling Radiative Heat Transfer in Fibrous Material: The Use of Plank Properties Compared to Spectral and Flux-Weighted Properties", Journal of Quantitative Spectroscopy and Radiative Heat Transfer, pp. 593603.

Aronson J. R., Emslie A. G., Ruccia F. E., Smallman C. R., Smith E. M., and Strong P.F., 1979, "Infrared emittance of fibrous materials", Applied Optics, Vol. 18, No. 15, pp.26222633.

ASHRAE, 1985, "Design Heat Transmission Coefficient", ASHRAE Handbook, Fundamental, chap. 23, American Society of Heating, Refrigerating and Air-conditioning Engineers, Atlanta, GA, pp. 23.1-23.22.

ASHRAE, 1993, "Thermal Insulation and Vapor Retarders-Fundamentals", ASHRAE Fundamentals Handbook (SI), pp. 20.1-20.21.

ASHRAE, 1997, "Heat Flow Factors Affecting Thermal Performance", ASHRAE Fundamentals Handbook (SI), pp. 22.4-22.5.

Asllanaj, F., Brige, X, and Jeandel, G. , 2007, "Transient Combined Radiation and Conduction in a One-dimensional Non-gray Participating Medium with Anisotropic Optical Properties Subjected to Radiative Flux at the Boundaries", Journal of Quantitative spectroscopy and Radiative Transfer, vol. 107, pp. 17-29.

Asllanaj F., Lacroix D., Jeandel G., Roche J., April 2003, “Transient Combined Radiation and Conductive Heat Transfer in Thermal Fibrous Insulation", Proceeding of Eurotherm 73 Computational Thermal Radiation in Participating Media 15-17, Mons, Belgium.

Asllanaj, F., Jeandel, G., and Roche, J. R. , 2001, "Numerical solution of Radiative Transfer Equation Coupled with Nonlinear Heat Conduction Equation", International Journal of Numerical Methods for Heat and Fluid Flow, vol. 11, no. 5, pp. 449-472.

Asllanaj, F., Jeandel, G., Roche, J. R., and Lacroix, D. , 2004, "Transient combined radiation and conduction heat transfer in fibrous media with temperature and flux boundary conditions", International Journal of Thermal Sciences, vol. 43, pp. 939-950.

Asllanaj F., Jeandel G., Roche J. R. , 2001, "Numerical solution of Radiative Transfer Equation Coupled with Nonlinear Heat Conduction Equation", International Journal of Numerical Methods for Heat and Fluid Flow, 11, 5, pp. 449-473.

Asllanaj, F., Milandri, A., Jeandel, G., and Roche, J. R., 1999, "Transfert de Chaleur Par Conduction et Rayonnement en Regime Transitoire dans Les Milieux Fibreux", IVe 
Colloque interuniversitaire franco-québécois Thermique des systèmes à température modérée.

Asllanaj, F., Milandri, A., Jeandel, G., and Roche, J. R. , 2002, "A Finite Difference Solution of Non-linear Systems of Radiative-conductive Heat Transfer Equations", International Journal of Numerical Methods in Engineering, vol. 54, pp. 1649-1668.

ASTM C612-93, 2002, "Mineral Fiber Block and Board Insulation, Specification for", American Society for Testing and Materials, Philadelphia.

ASTM C1335-96, 2005, Standard Test Method for Measuring Non-Fibrous Content of ManMade Rock and Slag Mineral Fiber Insulation, American Society for Testing and Materials, Annual Book of ASTM, part 04.06.

Bankvall, C.G. , 1972, "Natural Convective heat transfer in insulated structures", lund Institute of Technology, Report 38.

Bankvall C.G. , May 1973, "Heat Transfer in Fibrous Materials", Journal of Testing and Evaluation, Vol. 1, No. 5, pp. 235-243.

Bankvall C. G., 1974, "Mechanisms of Heat Transfer in Permeable Insulation and Their Investigation in a Special Guarded Hot Plate", Heat transmission measurements in thermal insulations, ASTM STP544, American Society for Testing and Materials, pp. 34-88.

Bhattacharyya R. K. , 1980, "Heat Transfer Model for Fibrous Insulations", Thermal Insulation Performance, ASTM STP 718, D. L. McElroy and R. P. Tye, Eds., American Society for Testing and Materials, pp.272-286.

Bommerg M., Klarsfeld S., January 1983, "Semi-empirical Model of Heat Transfer in Dry Mineral Fiber Insulations", Journal of Thermal Insulation, Volume 6, pp. 156-173.

Boulet P., Jeandel G., Morlat G., 1993, "Model of Radiative Transfer in Fibrous Media-Matrix Method", Int. J. Heat Mass Transfer, 36, pp. 4287-4297.

Boulet P., Jeandel G., Morlat G., Silberstein A., and Dedianous P., 1994, "Study of Radiative Behavior of Several Fiberglass Materials", Thermal Conductivity 22, edited by T. W. Tong, Technomatic, Lancaster, PA, pp. 749-759.

Budaiwi1 I., Abdou A., and Al-Homoud M., 2002, "Variations of Thermal Conductivity of Insulation Materials under Different Operating Temperatures: Impact on EnvelopeInduced Cooling Load", Journal of Architectural ENGINEERING, DECEMBER, pp. 125-132.

Buttner D., Fricke J., Reiss H. , 1985, "Analysis of the Radiative and Solid Conduction Components of the Thermal Conductivity of an Evacuated Glass Fiber Insulation: Measurement with a $700 \times 700 \mathrm{~mm}^{2}$ Variable Load Guarded Hot Plate Devise", in proceedings, 20th AIAA Thermophysics Conference, Williamsburg, Va., pp. 851019.

Cabannes F., Maurau J.C., Hyrien M., Klarsfeld S.M., 1979, "Radiative heat transfer in fiberglass insulating materials as related to their optical properties", High Temperatures - High Pressures, Vol.11, pp. 429-434.

Cohen L. D., Haracz R. D., Cohen A., and Acquista C., March 1983, "Scattering of Light from arbitrarily oriented finite cylinders", Applied Optics, Vol. 22, No. 5.

Cunnington G. R., and Lee S. C., 1996, "Radiative Properties of Fibrous Insulations: Theory Versus Experiment", J. of Thermophysics and Heat Transfer, Vo.10, No. 3, pp. 460466. 
Daryabeigi K., June 2002, "Heat Transfer in High-Temperature Fibrous Insulation", 8th AIAA/ASME joint Thermophysics and Heat Transfer Conference, 24-26, St.Louis, MO.

Daryabeigi, K., 1999, "Analysis and Testing of High Temperature Fibrous Insulation for Reusable Launch Vehicles", American Institute of Aeronautics and Astronaumics, AIAA-99-1044.

Degenne, M., Klarsfeld S., Barthe, M-P., 1978, "Measurement of the Thermal Resistance of Thick Low-Density Mineral Fiber Insulation", Thermal transmission Measurements of Insulations, ASTM STP 660, R. P. Tye, Ed., American Society for Testing and Materials, pp.130-144.

Dent, R. W. Skelton, J. and Donovan, J. G., 1990, "Radiant Heat Transfer in Extremely low Density Fibrous Assemblies", Insulation Materials, Testing, and Applications, ASTM STP 1030, D.L. McElory and J. F. Kimpflen, Eds., American Society for Testing and Materials, Philadelphia, pp. 79-105.

Dyrbol S., Elmroth A., Oct. 2002, "Experimental Investigation of the Effect of Natural Convection on Heat Transfer in Mineral Wool", Journal of Thermal Envelope \& Building Science, Vol. 26 Issue 2, p153, 12p.

Edmunds W. M. , 1989, "Residential Insulation", Energy conservation and ASTM standards.

EN 12664:2002, European Standard, Thermal performance of building materials and products - Determination of thermal resistance by means of guarded hot plate and heat flow meter methods - Dry and moist products of medium and low thermal resistance.

EN 12667:2001, European Standard, Thermal performance of building materials and products - Determination of thermal resistance by means of guarded hot plate and heat flow meter methods - Products of high and medium thermal resistance, European Committee for Standardization

EN 12939: 2000, European Standard, Thermal performance of building materials and products - Determination of thermal resistance by means of guarded hot plate and heat flow meter methods - Thick products of high and medium thermal resistance.

EN13162: 2001, European Standard, Thermal insulation products for buildings - Factory made mineral wool (MW) products - Specification.

Endriukaityte A., Bliudžius R.., Samajauskas R., 2004, "Investigation of Hydrothermal Performance of Fibrous Thermal Insulation Materials", Materials Science, Vol. 10, No. 1.

Fournier D., Klarsfeld S., 1974, "Some Recent Experimental Data on Glass Fiber Insulating Materials and Their Use for a Reliable Design of Insulations at Low Temperatures", Heat transmission Measurements in Thermal Insulations, ASTM STP 544, American Society for Testing and Materials, pp.223-242.

Frances De Ponte, 1985, "Present and Future Research on Guarded Hot Plates and Heat Flow Meter Apparatus", American Society for Testing and Materials, Philadelphia, pp. 101120.

Fricke J., Buttner D., Caps R., Gross J., Nilsson, O., 1990, "Solid conductivity of Loaded Fibrous Insulations", Insulation Materials, Testing and applications, ASTM STP 1030, D.L. McElory and J.F. Kimpflen, Eds., American Society for Testing and Materials, Philadelphia, pp. 66-78. 
Fricke J., Caps R., Hummer E., Doll G., Arduini M. C., De Ponte F., 1990, "Optically Thin Fibrous Insulations", Insulation Materials, Testing and Applications, ASTM STP 1030, D. L. McElory and J. F. Kimpflen, Eds., American Society for Testing and Materials, Philadelphia, pp. 575-586.

Guyer E. C., Brownell C. L., 1999 , "Handbook of Applied Thermal Design", Taylor \& Francis.

Goo N. S., Woo K., 2003, "Measurement and Prediction of Effective Thermal Conductivity for Woven Fabric Composites", International Journal of Modern Physics B, Vol. 17, Nos. 8 E 9, 1808-1813.

Guilbert G., Langlais C., Jeandel G., Morlot G., Klarsfeld S. , 1987, "Optical Characteristics of Semitransparent Porous Media", High Temperatures - High Pressures, Vol. 19, pp. 251-259.

Gustafsson S. E., Karawacki E., 1991, "Thermal Transport in Building Materials", Swedish Council for Building Research, Stockholm.

Hager N. E., Steere R. C., November 1967, "Radiant Heat Transfer in Fibrous Thermal Insulation", Journal of Applied Physics, vol. 38, No. 12, pp. 4663-4668.

Hokoi, S., Kumaran, M., K. , 1993, "Experimental and analytical investigations of simultaneous heat and moisture transport through glass fiber insulation", J. of Building Physics, 16(3): pp. 263-292.

Houston R. L. and Korpela S. A., 1982, "Heat Transfer Through Fiberglass Insulation", Proc. Of the Seventh International Heat Transfer Conference, Munch, 2,pp. 499-504.

Huetz-aubert, M., Klarsfeld, S., 1995, "Rayonnement thermique des matériaux semitransparents", Bases physiques, Techniques de l'ingénieur Extrait de la collection, B 8215, pp.26-27.

ISO 8301:1991 Thermal insulation - Determination of steady state thermal resistance and related properties - Heat flow meter apparatus.

Jauen J. L., Klarsfeld S., 1987, "Heat Transfer Through a Still Air Layer", Thermal Insulation: Materials and systems, ASTM STP 922, F. J. Powell and S. L. Mattews, Eds., American Society for Testing and Materials, Philadelphia, pp. 283-294.

Jonsson B., 1996, "The Relationship Between Thermal Conductivity and Density for Mineral Wool and Expanded Polystyrene", Proceedings of the $4^{\text {th }}$ Symposium of Bilding Physics in the Nordic Countaries, Finland, pp. 675-682.

Keller K., and Blumberg J., 1990, "High Temperature Airborne Fiber Insulations Heat Transfer", Proceedings of the Ninth International Heat Transfer Conference, Vol. 5, edited by G. Hetsroni, Hemisphrer, pp. 479-484.

Kielmeyer W. H. and Troyer R. L. , 1999, "Fibrous Insulations", Handbook of Applied Thermal Design, E.C. Guyer and C.L. Brownell, Eds., Taylor \& Francis, pp.3.123.22 .

Klarsfeld S., Boulant J., and Langlais C., 1987, "Thermal Conductivity of Insulants at High Temperature: Reference Materials and Standards", Thermal Insulation: Materials and Systems, ASTM STP 922, F. J. Powell and S. L. Matthews, Eds., American Society for Testing and Materials, Philadelphia, pp. 665-676.

Kumaran M. K. and Stephenson D. G., 1988, "Heat transport through fibrous insulation materials", J. of Building Physics, 11(4): pp. 263-269.

Langlais, C. and Boulant, J., 1990, "Use of Two Heat transducers for transient thermal measurements on porous insulating Materials", Insulation Materials, testing and 
applications, ASTM STP 1030, D. L. McElroy and J. F. Kimpflen, Eds. American Society for Testing and Materials, Philadelphia, PP. 510-521.

Langlais, C., Guilbert, G., and Klarsfeld, C., 1995, "Influence of the Chemical Composition of Glass on Heat Transfer through Glass Fiber Insulations in Relation to Their Morphology and Temperature Use", Journal of Thermal Insulation and Building Envelopes, vol. 18, pp. 350-376.

Langlais C., Hyrien M., Klarsfeld S., 1983, "Influence of Moisture on Heat Transfer through Fibrous Insulating Materials", Thermal Insulation, Materials and systems for Energy Conservation in the 80s, ASTM STP 789, F. A. Govan, D. M. Greason, J. D. McAllister, Eds., American Society for Testing and Materials, Philadelphia, pp. 563-581.

Langlais C., Klarsfeld S., 1985, "Transfert de chaleur a travers les isolants fibreux en relation avec leur morphologie", Journée D'etudes sur les Transferts Thermiques dans les Isolants Fibreux, pp. 1-34.

Langlais, C. Klarsfeld, S., 2004, "Isolation thermique à température ambiante", Bases physiques, Techniques de l'ingénieur Extrait de la collection, BE9 859, pp.1-17.

Larkin B. K., Churchill S. W., December 1959, "Heat Transfer by Radiation Through Porous Insulations", American Institute of Chemical Engineers Journal, Vol. 4, No. 5, pp. 467474.

Lee S. C., 1986, "Radiative Transfer through A Fibrous Medium: Allowance for Fiber Orientation", J. Quant. Spectrosc. Radiat. Transfer, Vol. 36, No. 3, pp. 253-263.

Lee S. C., 1988, "Radiational Heat-Transfer Model for Fibers Oriented Parallel to Diffuse Boundaries", J. Thermophysics, Vol. 2, No. 4.

Lee, S. C., 1989, "Effect of Fiber Orientation on Thermal Radiation in Fibrous Media", Int. J. Heat Mass Transfer, Vol. 32, No. 2, pp. 311-319.

Lee S. C., 1990, "Scattering Phase Function for Fibrous Media", Int. J. Heat Mass Transfer. Vol. 33, No. 10, pp. 2183-2190.

Lee S. C., Cunnington G. R., 1998, "Fiber Orientation Effect on Radiative Heat Transfer through Fiber Composites", proc. 7th AIAA/ASME Joint Thermophysics and Heat Transfer Conf., Albuquerque, NM, pp. 1-9.

Lee S. C., Cunnington G. R., 1998, "Heat Transfer in Fibrous Insulation: Comparison of Theory and Experiment", Journal of Thermophysics and Heat Transfer, Vol. 12, pp. 297-303.

Lee, S. C., Cunnington, G. R., 2000, "Conduction and Radiation Heat Transfer in Highporosity Fiber Thermal Insulation", Journal of Thermophysics and Heat Transfer, vol. 14, no.2, pp.121-136.

Matthews L. K., Viskanta R., and Incropera F. P., 1984, "Development of Inverse Methods for Determining Thermophysical and Radiative Properties of High Temperature Fibrous Materials", International Journal of Heat and Mass Transfer, Vol. 2, No.1, pp. 78-81.

Matthews L. K., Viskanta R., and Incropera F. P., 1985, "Combined Conduction and Radiation Heat Transfer in Porous Materials Heated by Intense Solar Radiation", Journal of Solar Energy, Vol. 107, pp. 29-34s.

McElroy D.L, Graves R. S., Yarbrough D.W. and Tong T. W. , 1986, "Non-Steady-State Behavior of Thermal Insulations", J. THERMAL INSULATION, Vol. 9, pp 236-249. 
Milandri, A., Asllanaj, F., and Jeandel, G. , 2002, "Determination of Radiative Properties of Fibrous Media by an Inverse Method- Comparison with the Mie Theory", Journal of Quantitative Spectroscopy and Radiative Transfer, vol. 74, no. 5, pp. 637-653.

Milandri A., Asllanaj F., Jeandel G. , 2002, "Determination of Radiative Properties of Fibrous Media by an Inverse Method- Comparison with the MIE Theory", Journal of Quantitative Spectroscopy and Radiative Transfer, 74, 5, pp. 637-653.

Milandri A., Asllanaj F., Jeandel G., and Roche, J. R. , 2002, "Heat transfer by Radiation and Conduction in Fibrous Media without Axial Symmetry", Journal of Quantitative spectroscopy and Radiative Transfer, vol. 74, pp. 585-603.

Milandri, A., Asllanaj, F., Jeandel, G., Roche, J. R., and Bugnon S., 1999, "Transfert de Chaleur Couple Par Rayonnement et Conduction en Regime Permanent dans des Milieux Fibreux Soumis a des Conditions de Flux et en l'absence de Symetrie Azimutale", IVe Colloque interuniversitaire franco-québécois Thermique des systèmes à température modérée.

Nicolau V. P., Raynard M., and Sacadura J. F., 1994 "Spectral Radiative Properties Identification of Fiber Insulating Materials", International Journal of Heat and Mass Transfer, Vol. 37, Supplement 1, pp. 311-324.

Nisipeanu, E., and Jones, P. D. , 2003, "Monte Carlo Simulation of Radiative Heat Transfer in Coarse Fibrous Media", Journal of Heat Transfer, vol. 125, no. 4, pp. 748-752.

Papadopoulos A. M., 2003, "State of the art in thermal insulation materials and aims for future developments", Energy and Buildings, 37, pp. 77-86.

Petrov V. A., 1997, "Combined Radiation and Conduction Heat Transfer in High Temperature Fiber Thermal Insulation", International Journal of Heat and Mass Transfers, Vol. 40, No. 9, pp. 2241-2247.

Rish J. W., Roux J. A. , January 1987 , "Heat Transfer Analysis of Fiberglass Insulations With and Without Foil Radiant Barriers", J. Thermophysics, Vol. 1, No. 1.

Roux J. A., Smith A. M., August 1977, "Combined conductive and Radiative Heat Transfer in a Absorbing and Scattering Medium", ASME Heat Transfer Conference.

Roux, J.A., 2003, "Radiative properties of high and low density fiberglass insulation in the 438.5 $\mu \mathrm{m}$ wavelength region", J. of Thermal Env. \& Bldg. Sci. 27(2), pp. 135-149.

Saatdjian E., Demars Y., Klarsfeld S., Buck Y. , 1983, "Effects of Binder Decomposition on High- Temperature Performance of Mineral Wool Insulation", Thermal Insulation, Materials and systems for Energy Conservation in the 80s, ASTM STP 789, F. A. Govan, D. M. Greason, and J. D. McAllister, Eds., American Society for Testing and Materials, Philadelphia, pp. 757-777.

Saboonchi A., Sutton W. H., and Love T. J., 1987, "Direct Determination of Gray Participating Thermal Radiation Properties of Insulating Materials", J. Thermophysics, Vo. 2, No. 2, pp. 97-103.

Shirtliffe C. J., 1981, "Effect of Thickness on the Thermal Properties of Thick Specimen of Low-Density Thermal Insulation", National Research Council Canada, No. 966.

Tong, T. W., Tien, C. L., 1980, "Analytical models for thermal radiation in fibrous insulations", Journal of Thermal Insulation and Building Envelopes, vol. 4, pp. 27-44.

Toor J. S., and Viskanta R., 1968, "A numerical Experiment of Radiant Heat Interchange by the Monte Carlo Method", Int. J. Heat Mass Transfer, Vo. 11, pp. 883-897.

Yeh H. Y., Roux J. A., 1990, "Transient coupled Conduction and Radiation Heat Transfer through Ceiling Fiberglass/Gypsum Board Composite", Insulation Materials, 
Testing and Applications, ASTM STP 1030, D. L. McElroy and J. F. Kimpflen, Eds. American Society for Testing and Materials, Philadelphia, pp.545-560.

Yuen W. W., Takara E., and Cunnigton G., 2003, "Combined Conductive/Radiative Heat Transfer in High Porosity Fibrous Insulation Materials: Theory and Experiment", Proc. $6^{\text {th }}$ ASME-JSME Thermal Engineering Joint Conference, Hawaii, USA.

Zeng, S. Q., Hunt, A. J. Greif, R. and Cao, W. , 1995, "Approximate Formulation for Coupled Conduction and radiation Through a Medium with Arbitrary Optical Thickness", Journal of Heat Transfer, vol. 117, pp. 797-799. 


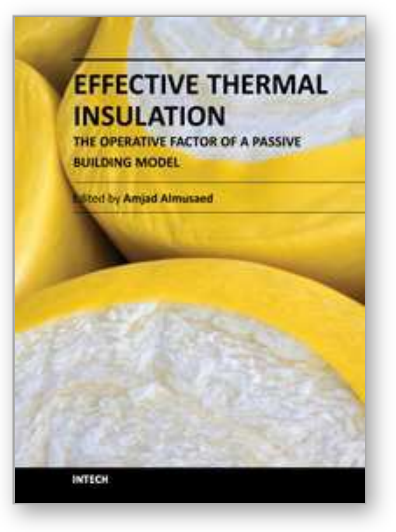

\author{
Effective Thermal Insulation - The Operative Factor of a Passive \\ Building Model \\ Edited by Dr. Amjad Almusaed
}

ISBN 978-953-51-0311-0

Hard cover, 102 pages

Publisher InTech

Published online 14, March, 2012

Published in print edition March, 2012

This book has been written to present elementary practical and efficient applications in saving energy concept, as well as propose a solitary action for this category of topics. The book aims to illustrate various methods in treatment the concept of thermal insulation such as processes and the attempt to build an efficient passive building model.

\title{
How to reference
}

In order to correctly reference this scholarly work, feel free to copy and paste the following:

Sohrab Veiseh (2012). A New Method for Numerical Modeling of Heat Transfer in Thermal Insulations Products, Effective Thermal Insulation - The Operative Factor of a Passive Building Model, Dr. Amjad Almusaed (Ed.), ISBN: 978-953-51-0311-0, InTech, Available from: http://www.intechopen.com/books/effective-thermal-insulation-the-operative-factor-of-a-passive-buildingmodel/a-new-method-for-numerical-modeling-of-heat-transfer-in-thermal-insulations-products

\section{INTECH}

open science | open minds

\section{InTech Europe}

University Campus STeP Ri

Slavka Krautzeka 83/A

51000 Rijeka, Croatia

Phone: +385 (51) 770447

Fax: +385 (51) 686166

www.intechopen.com

\section{InTech China}

Unit 405, Office Block, Hotel Equatorial Shanghai

No.65, Yan An Road (West), Shanghai, 200040, China

中国上海市延安西路65号上海国际贵都大饭店办公楼 405 单元

Phone: +86-21-62489820

Fax: $+86-21-62489821$ 
(C) 2012 The Author(s). Licensee IntechOpen. This is an open access article distributed under the terms of the Creative Commons Attribution 3.0 License, which permits unrestricted use, distribution, and reproduction in any medium, provided the original work is properly cited. 